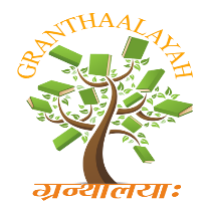

Social

\section{INTERNATIONAL JOURNAL OF RESEARCH - GRANTHAALAYAH \\ A knowledge Repository}

\title{
ALANKARAS IN RATNAVALI
}

\author{
Dr.Sujatha Raghavan *1 \\ ${ }^{* 1}$ Professor in Sahitya, Dept of Sanskrit \& IC, SCSVMV University, Enathur, Kanchipuram \\ Tamilnadu - 631561, INDIA
}

DOI: https://doi.org/10.29121/granthaalayah.v4.i10.2016.2501

\section{ABSTRACT}

RATNAVALI Drama was written by SRI HARSHA a famous poet in Sanskrit. It contains four acts. Udayana is the courages Hero and Rarnavali is heroine in this drama. The main sentiment in this drama is SRINGARA, and main Virtham is KOWSIKI. Here the author describes the love between Udayana and Ratnavali in heart touching and beautiful manner. Many types of Alankaras used for this purpose which was taken from Kuvalayananda.

Keywords:

Uadayana-ratnavali-sringara; rasa-kowsiki; vritam-kuvaayananda-upama; alankara-uthprksha; alankara-samasokthi; alankara-swapavokthi; alankara-kavyalingamalankara.

Cite This Article: Dr.Sujatha Raghavan, "ALANKARAS IN RATNAVALI" International Journal of Research - Granthaalayah, Vol. 4, No. 10 (2016): 126-131.

ललितः इयमपि नाटिका चतुराड्किकाः। तस्या कर्ता श्रीहर्षः। नायकः उदयनः धीरललिः। नायिका रत्रावली। कैशिकीवृत्तिः। अत्र श्रृड्गाररसः मुख्यः। सिंहलाधिपतेः सुताया रत्रावल्याः उदयनस्य च प्रेमप्रसड्ग्गे वर्णितः अस्ति। नागानन्दं हि पश्चाड्कं नाटकम्। नायकः जीमूतवाहनः धीरोदात्तः। नायिका च मलयवती। मुख्यरसः शान्तः। अत्र जीमूतवाहनस्य औदार्यं स्वनिपुणं चित्रितमस्ति। येषु च रत्रावली लक्षणशास्तिभिर्धनि कविविश्वनाथप्रभृतिः नाट्यशास्रलक्षण सम्मतेति सादरमुदृधृता दृश्यते। श्रीहर्षस्यू शैली सरसा सरला वैदर्भीप्रधाना च।

रत्रावल्यां अलड्क्कारलक्षणानि कुवलयानन्दात् स्वीकृतानि। कुवलयानन्दः इति अलड्कार ग्रन्थः अप्पयदीक्षितेन लिखितः। ग्रन्थे अलड्काराः तेषां लक्षणानि सन्ति।

१. उपमालड्कार:

उपमा यत्र सादृश्य लक्षमी रुल्लसति द्वयोः।1

उदाहरणम्- 


\section{परिपाण्डुना मुखेन प्रियमिव हृदयास्थितं रमणी।।2}

एषा पूर्वदिशा सर्वतः पाणडुवर्णेन मुखेन निशानाथं चन्द्रमुदयगिरेः पूर्वपर्वतस्य तटेन क्षेत्रेण व्यवहितं सूचयति। यथा रमणी प्रोषितभर्तुका परिपाण्डुना मुखेन प्रियं हृदयस्थितिं सूचयति तथा। अत्र उपमालड्कारः प्रयोगं अस्ति।

२. उत्प्रेक्षालड्कारः

$$
\begin{aligned}
& \text { संभवनास्यादुत्प्रेक्षा वस्तुहेतुफलात्मना। } \\
& \text { उक्तानुक्तास्पदाद्यात्र सिद्धाउसिद्धास्पदे पदे।।3}
\end{aligned}
$$

उदाहरणम्

$$
\begin{aligned}
& \text { उद्यद्विद्वुमकान्तिभिः किसलंयैस्ताम्रां त्विषां बिभ्रतो } \\
& \text { भृड्ग्गलीविरुतैः कलैरविशदव्याहारलीलाभृतः। } \\
& \text { घर्णान्तोमलयानिलाहतिचलैः शखासमूहैर्मुहुः } \\
& \text { भान्ति प्राप्य मधुप्रसड्गमधधुना मत्ता इवामि द्रुमाः।।4 }
\end{aligned}
$$

अधिना मद्यस्य सम्पर्क प्राप्य उद्यतामुदगच्छतां प्रबलानां कान्तिरिव पल्लवैः मरुणां द्युतिं धारयन्तः। कलैः मधुरास्पुटैः भ्रमश्राणीनां हारस्य विलासं बिभ्रति। दक्षिणवातस्य चश्चलैः विटपसमूहैः पुनः घूर्णन्तो मत्ता इव प्रकाशन्ते। अत्र उत्प्रेक्षालड्कारः भवति।

३. समासोक्त्यालड्कारः

$$
\text { समासोक्तिः परिस्फुर्तिः प्रस्तुते उप्रस्तुत चेत्।5 }
$$

उदाहरणम्

$$
\begin{aligned}
& \text { यातोस्मि पद्मनयने समयो ममैष } \\
& \text { सुप्ता मयैव भवती प्रतिबोधनीया। } \\
& \text { प्रत्यायनामयमितीव सरोरुहिणयाः } \\
& \text { सूर्योडस्तमस्तकनिविष्टकरः करोति।।6 }
\end{aligned}
$$

हे पद्मनयने! प्रस्थितमस्मि अयं मम गमनावसरः। निद्रां उपागतं त्वं मया एव सूर्येनेव उद्वोधनीय अस्तचलशिखरे स्थिताः किरणाः तादृशः दृश्यमानः दिनकरः कमलिन्याः आश्वासनं करोति। अत्र कमलिनि सूर्यवृत्तान्त व्याजेन नायिकानायकयोः भावि वृत्तान्तः स्वचितः तदर्थं अत्र समासोक्तिः।

४. स्वभावोक्त्यलड्कारः

स्वभावोक्तिः स्वाभावस्य जात्यादिस्थस्य वर्णनम्। ${ }^{7}$ 


\section{द्वयोदृष्ट्वालापं कलयति कथामात्मविषयाम्। सुखीषु स्मरासु प्रकटयति वैलक्ष्यमधिकम् \\ प्रिया प्रायेणास्ते हृदयनिहितान्तङ्कविधुरा।।8}

राजाभिलाषतया ज्ञातस्मि इति मत्वा वल्लभा बाहुल्येन यावत् हृदयस्थितः यः भातिः विकला वर्तते। सागरिका लज्जया निखिलस्य वदनं व्यावर्तयति। जनयो: परस्परकथोपकथनं दुष्ट्वा स्वसम्बन्धिनीं वार्तां अवधारयति। सहचरीषु ईषद्वान्तीषु अत्यन्तं लज्ञां प्रकटयति। अत्र श्रोके शड्काव्यभिचारीभावः संदर्शितः तथैव स्वभावोक्त्यालड्कारः।

५. काव्यलिड्गमलड्कार:

समर्थनीयस्यार्थस्य काव्यलिड्गं समर्थनम्।9

उदाहरणम्

$$
\begin{aligned}
& \text { भुभुक्गे सहसोदूते गि वदनं नीतं परां नम्रता- } \\
& \text { मीषन्मां प्रति भेदकारि हसितं नोक्तं वचो निष्ठुरम्। } \\
& \text { अन्तर्बाष्पजडीकृतं प्रभुतया चक्षुर्न विस्फारितं } \\
& \text { कोपश्च प्रकटीकृतो दयितया मुक्तश्च न प्रश्चः।110 }
\end{aligned}
$$

प्रियमया वासवदत्ताया कर्तुं समर्थतया भुवोर्भड्नग्त तत्क्षण आविर्भुतोपि मुखं शयवतीं नम्रतां प्रापितम्। ममुद्विश्य मुखं प्रणयविद्वंशी अल्पं हसितं कृतः। कठोर वचः न उक्तम्। अन्तबोस्पेन मन्दीतं नयनं न उन्मीलितम्। तस्मात् प्रियया कोपः प्रकाशितः। प्रणयश्च न मुक्तः। अत्र प्रथमपादत्रयोक्त वाक्यार्थानां चतुर्थचरणोक्तं प्रति हेतुत्वात् काव्यलिड्गमलड्क्कारः।

६. अर्थान्तरान्यासालड्कारः

$$
\text { उत्तिरर्थान्तरन्यासः स्यात् सामान्यविशेषयोः|11 }
$$

विषयोः सामान्यसमर्थनरुपस्य अर्थान्तरन्यासलड्कारः

\section{उदाहरणम्}

दुर्वारां कुसुमशख्यथां वहन्त्या

कामिन्या यदभिहितं पुरः सखीनामा।

तद्भूयः शिशुशुकसारिकाभिरूत्तं

\section{धन्यानां श्रवणपथतिथित्वमेति।12}

दुःखेन आर्थते या तां कामदेवस्य पीडां धारयन्त्या तरुण्यां सुखीनां पुरः यद् उक्तम्। तत् शिशुभिः सागरिकाभिः पुनः कथितम्। पुण्यवतां पुरुषानां श्रवणपयः अतिथित्वं प्राप्रोति। दूरभाषितं तद्वयनस्य साक्षाच्छ्रवणं पक्षिभिरूचरि पुनस्तद्वचनं येषां कर्णगोचरी भवति ते धन्या इति भावः अत्र अर्थान्तरन्यासालड्कारः। 
७. रूपकालड्कार:

\section{विषप्यभेदाद्वुप्यरअंनं विषयस्य यत्। रूपकं तत् त्रिधाधिक्यन्यूनत्वानुभयेक्तिभिः।13}

उदाहरणम्

$$
\begin{aligned}
& \text { विरम विरम वहने मुश्च धूमानुबन्धं } \\
& \text { प्रकटयसि किमुच्चैरचिषां चक्रवाल्यम्। } \\
& \text { विरहहुतभुजाऽहं यो न दग्धः प्रियायाः } \\
& \text { प्रलयदहनभासा तस्य किं त्वं करोषि।।14 }
\end{aligned}
$$

हे वहने! त्वं विरम विरम धूमोत्पातं त्यज। ज्वलानां मण्डलं किमर्थं विस्तारयसि यः अहं वत्सराज उदयनः प्रियतमायाः प्रलयकालाग्रि तुल्यतेजसा विरहहुतभुजां न ज्वालितः। त्वं किं करोषि?। विफलमिति भावः तदर्थं रूपकालड्क्कारः।

\section{८. विभावनालड्कार:}

विभावना विनापि स्यात् कारणं कार्यजन्म चेत्। 15 कारणं विना कार्यस्य उत्पत्तिः भवति चेत् विभावनालड्कारः। क्रियायाः प्रतिषेधेऽपि फलव्यक्तिविभावना। उदाहरणम्

$$
\begin{aligned}
& \text { मनश्वलं प्रकृत्यैव दुर्लक्ष्यं च तथापि मे। } \\
& \text { कामेनैतत्कथं विद्धं समं सर्वैः शिलीमुखैः।।16 }
\end{aligned}
$$

चित्तं स्वाभावेन चश्चलं लक्षयितुं अशक्यश्व तथापि मनसः चलत्वे सूक्ष्मत्वे सत्यपि मम मनः अनङ्गेन निखिलै: भाणैः तुल्यकालं केन प्रकारेण भिन्नः। अत्र कारणं विना कार्यस्य उत्पत्तिः तथैव विभावनालड्कारः।

९. विरोधाभासालङ्कार:

\section{आभासत्वे विरोधस्य विरोधाभास इष्यते। 17}

\section{उदाहरणम्}

किं धरण्यां मृगाड्कः आकाशे महीधरो जले ज्वलनः।

\section{मध्याहने प्रदोषो दर्श्यतां देहभाज्ञात्मि।18}

किं पृथिव्यां चन्द्रः नभसि पर्वतः सलिले अग्रिः मध्याहनकाले सायंकालः प्राप्यतां आदेशय। अत्र विरोधाभासत्वे भवति तथैव विरोधाभासालड्कारः।

१०. प्रतीपालड्कारः 


\section{प्रतीपमुपानस्योपमेयत्वप्रल्पनम्। आक्षेप उपमानस्य प्रदीपम उपमेयता।।19 इति}

उदाहरणम

\section{किं पद्मस्य रुचं न हन्ति नयनानन्दं विधते न किं वृद्धिं वा ज्ञाकेतनस्य कुरुते नालोकमात्रेण किम्। वक्त्रेन्द्रौ तव सत्ययं पदपरः शीतांशुरभ्युद्रतो दर्षः स्यादमृतेन चेदिह तदप्येवास्ति बिम्बाधरे।।20}

तव वक्त्रेन्दुः कमलस्य त्विषं न पराजयति किम्? नेत्राणां आनन्दमाहलादकत्वं न विद्यते किम्। अथवा आलोकमात्रेण कन्दर्पस्य उद्वीपुं न विदधातिकिम्। यस्मात् भवत्याः चन्द्रवदनेविद्यमाने दृश्यमानः स्वमुखात् अतिरिक्तः शुरिन्दुः उदितः।

चेद्यपि सुधया चन्द्रस्य अलड्कारः भवेत्। अमृतमपि अस्मिन् तव बिम्बफलतुल्याधरोष्ठे वर्तते एव। अत्र प्रतिपालड्कारः।

उपसंहार:

श्रीहर्षस्य रूपकत्रये रत्रावली अत्यन्तं प्रसिद्धम्। अनेन प्रकारेण रत्रावल्याः अलड्काराः सन्ति। आलड्कारिकै: स्वग्रन्थेषु बहुत्र रत्रावली श्लोकाः उदाहरणत्वेन दर्शिताः दृश्यन्ते।

\section{उपयुक्तग्रन्थसूची}

१. कुवलयानन्दः -- अप्पय्यदीक्षितः चौखाम्बा १९९३

२. कुवलयानन्द: -- भोलाशंकर व्यस(हिन्दी अनुवादम्) चौखाम्बा १९९३

३. रत्नावली -- M.R. Kale चौखाम्बा, चौखाम्बा १९९३

\section{अध्यायान्त टिप्पणी}

१. कुवलयानन्दम्. ६

२. रत्रावलायाम्. २४

३. कुवलयानन्दम्. २ २

४. रत्रावलायाम्. १.२७

५. कुवलयानन्दम्. ३ ?

६. रत्रावलायाम्. ३.६

७. कुवलयानन्दम्. ? ६०

८. रत्रावलायाम्. ३.४

९. कुवलयानन्दम्. ? २? 
१०. रत्नावलायाम्.२.२२

११. कुवलयानन्दम्. १२२

१२. रत्नावलायाम्. २.७

१३. कुवलयानन्दम्. ? ७

१४. रत्नावलायाम्. ४.२६

१५. कुवलयानन्दम्.७७

१६. रत्नावलायाम्.३.२

१७. कुवलयानन्दम्.७६

१८. रत्नावलायाम्. ४.८

१९. कुवलयानन्दम्. ?

२०. रत्तावलायाम्.३.२३ 